\title{
基于 Excel 宏程序的煤矿供电自动计算
}

\section{Automatic Calculation of Coal Mine Power Supply Based on Excel Macro Program \\ 阎胜国 ${ }^{1}$ 苑昌明 ${ }^{2}$ 阎胜军 ${ }^{2}$ 邱唯一 ${ }^{2}$}

\author{
Shengguo Yan ${ }^{1}$ Changming Yuan ${ }^{2}$ Shengjun Yan ${ }^{2}$ Weiyi Qiu ${ }^{2}$
}

\section{1.阜新市平安矿业有限责任公司 中国·辽宁 阜新 123000}

\section{2. 阜新市海州区应急保障和市场安监执} 法中心

中国·辽宁 阜新 123000

1.Fuxin Ping' an Mining Co., Ltd.,

Fuxin, Liaoning, 123000, China

2.Fuxin Haizhou District Emergency Support and

Market Security Supervision Law Enforcement

Center,

Fuxin, Liaoning, 123000, China
【摘 要】利用 Excel 强大的计算功能,实现供电设计的自动计算, 并且利用 Office 提供的 宏程序, 实现了供电设计中电气设备布置图的调用和校验。完成了供电设备布置示意图、 电流整定校验、自动生成供电设计报告。系统简单好用,经过现场实践, 实现了供电设计精 准计算的功能。

【Abstract】The powerful calculation function of Excel is used to realize the automatic calculation of power supply design, and the macro program provided by Office is used to realize the call and check of the electrical equipment layout in power supply design. The layout diagram of power supply equipment, current setting and calibration are completed, and the power supply design report is generated automatically. The system is simple and easy to use. Through the field practice, the function of accurate calculation of power supply design is realized.

【关键词】供电设计;Excel; 自动计算

【Keywords \power supply design; Excel; automatic calculation

【DOI】10.36012/peti.v2i1.1278

\section{1 引言}

长期以来, 煤矿供电设计计算依靠技术人员手工计算, 随着煤矿机械化、自动化的发展, 煤矿机械设备的功率越来 越大, 供电距离也越来越长, 而且有的煤矿(如阜新地区地质 条件限制较大的煤矿)搬家倒面的频率也比较高, 或者工作 面的设备增减对供电设计的验算等,手工计算供电设计给技 术人员带来大量处理复杂数据的麻烦, 有的计算过程还要结 合前面计算的结果去校验后面的短路电流值、启动网络压降 等数据, 计算繁琐, 容易出错 ${ }^{[1,2]}$ 。为了解决这个问题, 文章在 基于成熟的 Excel 办公软件的基础上，开发设计了适合本地 区煤矿的供电设计系统, 实现了精准安全供电的同时提高了 生成效率。

\section{2 系统功能的实现}

根据中国国家标准和行业标准的要求,如 GB/T 504172017《煤矿井下供配电设计规范》和《煤矿井下低压电网短路
保护装置的整定细则》等要求, 又根据煤矿长期形成的供电设 计格式、矿井实际情况等灵活应用 ${ }^{[3 \sim 7]}$ 。只要电脑安装了 Office 办公软件,把设计文档拷贝过来就能应用了。

文档设置了明显的输入、计算格式, 只要设计人员按照预 选定的设备参数填写进红色区域, 蓝色区域已经固化好的计 算公式就会自动得出计算结果，实际这个过程已经在后台定 义好了区域名称, 在以后的计算中, 要用到上面表格的数据, 计算机根据区域名称和索引自动查找计算, 避免了以前手工 计算时不断翻看校验数据的过程(如图 1 所示)。

\begin{tabular}{|c|c|c|c|c|c|c|c|c|}
\hline 设备名称 & 设备型号 & $\begin{array}{c}\text { 单机功率 } \\
(\mathrm{kW})\end{array}$ & 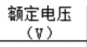 & 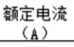 & $\begin{array}{c}\begin{array}{c}\text { 起动电流 } \\
(\mathrm{A})\end{array} \\
\end{array}$ & \begin{tabular}{|}
$\mid$ |每组电 \\
机台数
\end{tabular} & 繁组动 & 使用地点 \\
\hline 采煤机 & \begin{tabular}{|c|}
$16300 / 700^{-}$ \\
$\mathbb{N D}$
\end{tabular} & 300 & 1140 & 256 & 1311 & 5 & 700 & 工作面 \\
\hline 转载机高速 & SGZ764/630 & 315 & 1140 & 199 & 1196 & 1 & 315 & 运顺 \\
\hline 转载机低速 & SGZ7644/630 & 160 & 1140 & 135 & 810 & 1 & 160 & 运顺 \\
\hline 3\#乳化洜 & BRW $200 / 31.5$ & 125 & 1140 & 79 & 475 & 1 & 125 & 运顺 \\
\hline 2\#喷要泉 & BPR315/6.3 & 45 & 1140 & 28 & 171 & 1 & 45 & 运顺 \\
\hline 控制台 & ZBZ-4. OM & 4 & 1144 & 2 & 12 & & 4 & 运顺 \\
\hline B1系统 & & & 电流合计 & 565 & 功率合计 & & 1189 & \\
\hline
\end{tabular}

图 1 设备参数录入表格

系统根据宏程序, 启动了图形文件调用功能, 实现了根据 
电力设计 Power Design

给定的设备生成供电系统示意图。具体实现方式为设计人员 根据本矿区的图例，画出基本图例图形，然后保存为 png 格 式,png 格式图片为透明图形图片,这样就实现了图形与说明 文字共存, 以供设计人员校验参考。如果有不当之处, 能灵活 进行修改设计(如图 2 所示)。

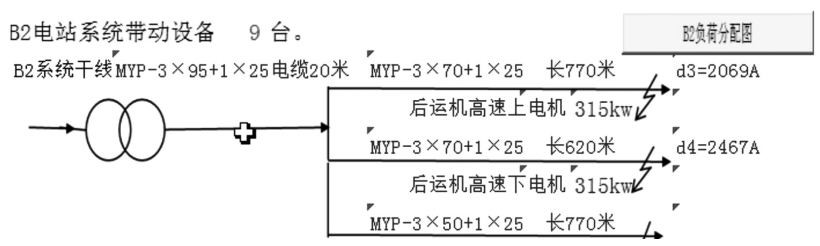

图 2 供电负荷分配调用部分截图

图 2 中, Excel 的宏程序实际是应用了 VBA 的程序代码, 可以根据给定的设备情况自动生成负荷分配图, 这是给设计 人员的一个保留的过程, 设计人员查看到此步骤后, 根据情况 校验参数, 然后点击“负荷分配图” 的按钮, 程序就根据参数的 坐标自动添加示例图形, 实现了图形和参数的结合, 供设计人 员校验。

本计算设计后台录人了煤矿常用的电缆的千米电阻、电 抗的参数, 录入了多个厂商提供的煤矿用干式移动变电站的 功率、损耗等参数,使用时只要按照图 1 所示的表格样式填入 所选电缆、变电站型号, 系统就会根据电缆、变电站和设备的 参数自动计算出设备运行时网络电压损耗、主要设备启动时 网络压降损失以及用电设备末端短路电流值的校验。为技术 人员提供参考。

本供电自动设计系统实行分块运算, 分块设计。即单个 采煤工作面有单个系统供电设计, 掘进工作面系统有单个掘 进面供电设计,各个分块设计系统之间利用公式定义了本区 域的消耗电流、电压损耗等参数, 并向外提供了名称和参数 供上级变电所供电设计计算参考使用, 为矿井供电设计提供 参考。

\section{3 应用对比}

\section{1 与其他软件对比}

网络上也能查到其他的供电设计软件系统, 有利用 GIS 系统软件的,有利用其他平台的 ${ }^{[8-10]}$, 但在某些地区和煤矿并 没有应用那些系统或平台, 因为那是要付费购买的,有的软 件还要求操作人员有一定的软件操作水平, 对于某些煤矿 和技术人员来说还是不能满足要求的。但本供电设计采用 的是成熟已久的 Office 办公软件中的 Excel 文件系统，办公
软件系统已经普遍应用于实际操作中,操作人员只要按照要 求正确录入参数, 就自动生成校验值, 实现了简单好用的 “俊瓜式”操作。

\section{2 与传统的手工计算比较}

突出的优点是计算精确。避免了手工计算时四舍五入累 计的误差, 避免了手工计算时上下查找对比的操作误差; 操 作便捷, 提高了效率。以前需要几天完成的供电设计计算, 应 用本系统只要几个小时, 操作成熟后可以不到一个小时就完 成。迅速快捷, 适于应急。临时发生事故, 手工计算时间是来 不及的, 中国辽宁省阜新市某地方煤矿就利用本供电计算系 统, 预测了某处发生水灾, 及时避免了排水供电系统问题的 出现。

\section{4 结语}

基于 Excel 宏程序的煤矿供电自动计算系统, 实现了办 公自动化和数据共享, 提高了劳动效率, 减轻了劳动强度, 消 除了人为误差, 进一步提高了设计的可靠性、准确性, 为矿区 机电设计及无纸化办公奠定了基础。

\section{参考文献}

[1]董哲.面向供电可靠性的配电自动化系统规划[J].电子技术与 软件工程,2018(15):97.

[2]贾海燕.煤矿地面供电系统及其自动化研究[J].机械管理开发, 2018,33(7):201-202.

[3]周燕.电力供电系统的无功补偿自动控制设计[J].山东工业技 术,2018(8):190.

[4]曾苛.煤矿地面供电综合自动化系统设计初探 [J].电子世界, 2018(6):35-36

[5]高希睿.矿井地面供电自动化系统分析[J].机电工程技术,2018, 47(3):107-108+158.

[6]刘跃.煤矿生产自动化控制的供电系统改造与应用[J].矿业装 备,2017(5):36-37.

[7]崔玉林.变电站自动化供电系统的设计与实现 [J].电子技术与 软件工程,2017(6):129.

[8]王博闻.供电系统电气工程及自动化控制技术 $[\mathrm{J}]$.电子制作, 2016(24):48

[9]罗宇.供电系统电气工程及自动化控制技术 $[\mathrm{J}]$. 黑龙江科学, 2016,7(19):64-65.

[10]张飞.煤矿供电系统自动化设计及实践研究 [J]. 价值工程, 2016,35(19):91-93. 